\title{
Differential regulation of mouse embryo development and viability by amino acids
}

\author{
M. Lane and D. K. Gardner* \\ Laboratories of Human and Animal Reproductive Biology, Institute of Reproduction and Development, \\ Monash University, Monash Medical Centre, Level 5, 246 Clayton Road, Clayton, Victoria, \\ Australia 3168
}

\begin{abstract}
The amino acid requirements of the preimplantation mouse embryo in culture changes as development proceeds from the zygote to the blastocyst stage. Eagle's non-essential amino acids and glutamine significantly increased cleavage rates during the first four cell cycles, while Eagle's essential amino acids without glutamine did not confer any benefit to embryo development before the eight-cell stage. After the eight-cell stage, non-essential amino acids and glutamine no longer stimulated cleavage rates but significantly increased blastocoel development and blastocyst hatching. In contrast, after the eight-cell stage essential amino acids increased cleavage rates as well as stimulating development of the inner cell mass of the resultant blastocysts. Fetal development after transfer of blastocysts was also significantly increased by culture with essential amino acids from the eight-cell stage. Consequently highest rates of development in vitro and viability after transfer were achieved when embryos were cultured with non-essential amino acids and glutamine to the eight-cell stage followed by development to the blastocyst stage in the presence of all 20 amino acids. Analysis of the parameters measured revealed a significant relationship between number of blastocyst cells and inner cell mass development with viability after transfer. Blastocyst formation and hatching could not be used to assess subsequent developmental potential.
\end{abstract}

\section{Introduction}

Fluid of the female reproductive tract contains significant concentrations of free amino acids (Menezo, 1972; Miller and Schultz, 1987). Furthermore, oocytes and embryos maintain an endogenous pool of amino acids (Schultz et al., 1981) as well as possessing carriers for specific amino acids (Van Winkle, 1988). However, most media designed for the culture of preimplantation mammalian embryos lack amino acids and are based on balanced salt solutions with added carbohydrate energy substrates and albumin (Whittingham, 1971; Quinn et al., 1985; Gardner and Lane, 1993a; Bavister, 1995). Embryos cultured in such media exhibit delayed cleavage rates (Bowman and McLaren, 1970a), developmental arrest at species-specific stages (Bavister, 1987; Telford et al., 1990) and reduced viability after transfer (Bowman and McLaren, 1970b; Lane and Gardner, 1992).

Supplementation of culture media with specific amino acids has been shown to increase embryo development in vitro in several species including hamsters (Bavister and McKiernan, 1993; Bavister, 1995), different strains of mice (Mehta and Kiessling, 1990; Gardner and Lane, 1993, 1996; Ho et al., 1995), rats (Miyoshi et al., 1995), sheep (Thompson et al., 1992, 1995; Gardner et al., 1994) and cows (Takahashi and First, 1992; Gardner, 1994). In mice, it has been shown that

*Correspondence.

Received 5 August 1996. development of zygotes to the blastocyst stage is significantly improved by culture in the presence of Eagle's non-essential amino acids and glutamine (Gardner and Lane, 1993b). In contrast, zygotes cultured in the presence of essential amino acids without glutamine exhibit a significantly reduced number of blastocyst cells (Gardner and Lane, 1993b). Subsequent work determined that culture with non-essential amino acids and glutamine from the zygote to the six- to eight-cell stage significantly increased fetal development after transfer. Furthermore, non-essential amino acids and glutamine increased implantation rates but not fetal development after transfer at the morula and blastocyst stages of development. Development of the zygote in the presence of essential amino acids without glutamine to the six- to eight-cell stage had no effect on implantation rates or fetal development; however, the resultant fetuses were lighter than embryos cultured in the absence of any amino acids. In contrast to the observed detrimental effects of essential amino acids without glutamine in culture, fetal development was actually increased by culture of zygotes to the morula or blastocyst stages before transfer in the presence of this group of amino acids (Lane and Gardner, 1994). It is possible therefore that the preimplantation mouse embryo undergoes changes in its requirements for amino acids as it develops in order to maintain viability. The aim of this study was therefore to assess differential effects of amino acids on embryo development. Embryo development after culture with non-essential amino acids and glutamine, essential amino acids without glutamine and all 20 Eagle's amino acids 
(Eagle, 1959) was assessed using number of cells, blastocyst formation and hatching, and development of cell lineages within the blastocyst (inner cell mass and trophectoderm). The outgrowth ability and glycolytic activity of resultant blastocysts were also assessed. All parameters to assess embryo development were subsequently correlated with viability after transfer.

\section{Materials and Methods}

\section{Animals}

Embryos were obtained from 4-6 week old female FI hybrid $(\mathrm{C} 57 \mathrm{BL} / 6 \times \mathrm{CBA} / \mathrm{Ca})$ mice. Multiple ovulations were induced by 5 iu of pregnant mares' serum gonadotrophin (Folligon, Intervet, Lyppard, Victoria) followed $48 \mathrm{~h}$ later by 5 iu human chorionic gonadotrophin (hCG, Chorulon, Intervet). Females were placed with males of the same strain following the administration of hCG and the presence of a vaginal plug the following morning indicated that mating had taken place.

\section{Media}

Media used for embryo culture were based on modified mouse tubal fluid medium (mMTF; Gardner and Lane, 1993b) and had the following composition: $98.4 \mathrm{mmol} \mathrm{NaCl} 1^{-1}$ $4.79 \mathrm{mmol} \mathrm{KCl} \mathrm{l^{-1 }}, 1.19 \mathrm{mmol} \mathrm{KH}_{2} \mathrm{PO}_{4} \mathrm{l}^{-1}, 1.71 \mathrm{mmol}$ $\mathrm{CaCl}_{2} \cdot 2 \mathrm{H}_{2} \mathrm{O} \quad 1^{-1}, \quad 1.19 \mathrm{mmol} \quad \mathrm{MgSO}_{4} \cdot 7 \mathrm{H}_{2} \mathrm{O} \quad 1^{-1}$, $25.00 \mathrm{mmol} \mathrm{NaHCO}_{3} 1^{-1}, 0.37 \mathrm{mmol}$ sodium pyruvate $\mathrm{I}^{-1}, 4.79 \mathrm{mmol} \mathrm{D} / \mathrm{L}$-sodium lactate $\mathrm{l}^{-1}, 3.40 \mathrm{mmol}$ glucose $\mathrm{l}^{-1}$, $0.06 \mathrm{~g}$ penicillin $\mathrm{l}^{-1}, 0.05 \mathrm{~g}$ streptomycin $\mathrm{l}^{-1}, 0.01$ phenol red $1^{-1}$ and $4 \mathrm{~g}$ bovine serum albumin $1^{-1}$ (Miles Pentex Crystalline, Bayer Diagnostics, Kankakee, IL, lot 97). All salts were analar grade (BDH, Poole); glucose, sodium pyruvate, sodium lactate and antibiotics were embryo tested grade (Sigma Chemical Company, St Louis, MO). Eagle's nonessential and essential amino acids (Eagle, 1959) were purchased from ICN Biomedicals (NSW) and glutamine (Sigma) was added at $1.0 \mathrm{mmol} \mathrm{I}^{-1}$ (Table 1). Media were prepared with water of tissue culture grade purchased from CSL (Parkville, Victoria, Australia). The osmolarity of the media was maintained at $260-270$ mosmol by adjusting the sodium chloride content when amino acids were included in the formulation. In medium for embryo collection and manipulation, $20 \mathrm{mmol} \mathrm{NaHCO} \mathrm{I}^{-1}$ was replaced by $20 \mathrm{mmol}$ Hepes $\mathrm{I}^{-1}$ (Sigma) at pH 7.4 (H-MTF).

\section{Embryo collection}

Cumulus enclosed zygotes were collected at $21 \mathrm{~h}$ after hCG treatment and denuded by incubation for less than $1 \mathrm{~min}$ with $1.0 \mathrm{mg}$ hyularonidase $\mathrm{ml}^{-1}$ (Bovine Testes, Sigma) in H-MTF. Embryos collected at the eight-cell stage were flushed from the utero-tubal junction at $63 \mathrm{~h}$ after hCG in H-MTF. Blastocysts were flushed from the uteri at $88 \mathrm{~h}$ after hCG treatment. All embryos were washed three times in H-MTF and once in the appropriate culture medium before being placed in the culture drop.
Table 1. Concentrations of amino acids used to supplement medium mMTF

\begin{tabular}{ll}
\hline Amino acids & $\begin{array}{c}\text { Concentration } \\
\text { (mmol } 1^{-1} \text { ) }\end{array}$ \\
\hline $\begin{array}{l}\text { Non-essential amino acids } \\
\text { Alanine }\end{array}$ & 0.1 \\
Asparagine & 0.1 \\
Aspartate & 0.1 \\
Glutamate & 0.1 \\
Glycine & 0.1 \\
Proline & 0.1 \\
Serine & 0.1 \\
Essential amino acids & \\
Arginine & 0.6 \\
Cysteine & 0.1 \\
Glutamine & 1.0 \\
Histidine & 0.2 \\
Isoleucine & 0.4 \\
Leucine & 0.4 \\
Lysine & 0.4 \\
Methionine & 0.1 \\
Phenylalanine & 0.2 \\
Threonine & 0.4 \\
Tryptophan & 0.05 \\
Tyrosine & 0.2 \\
Valine & 0.4 \\
\hline
\end{tabular}

mMTF: modified mouse tubal fluid medium.

\section{Embryo culture}

All embryos were cultured in $20 \mu \mathrm{l}$ drops of medium in groups of 10 (Lane and Gardner, 1992) in $35 \mathrm{~mm}$ Primaria petri dishes (Falcon, Becton-Dickinson, Victoria, Australia) under $3.5 \mathrm{ml}$ of light mineral oil (Sigma) at $37^{\circ} \mathrm{C}$ in $5 \% \mathrm{CO}_{2}$ in air. Zygotes were cultured in either mMTF, mMTF supplemented with non-essential amino acids and glutamine, mMTF supplemented with essential amino acids without glutamine or mMTF with all 20 of Eagle's amino acids for $48 \mathrm{~h}$. Embryos cultured in each amino acid treatment were subsequently transferred to one of each of the three amino acid treatments to give a total of nine treatment groups and cultured for a further $48 \mathrm{~h}$ (Fig. 1). After $48 \mathrm{~h}$ of culture embryos in mMTF were transferred to fresh mMTF medium as a control without amino acids. Eight-cell embryos developed in vivo were cultured for $48 \mathrm{~h}$ only. The role of glutamine on blastocyst development was investigated further by culturing eight-cell embryos with non-essential amino acids without glutamine and essential amino acids with glutamine.

\section{Embryo morphology}

Embryo morphology was assessed using phase contrast microscopy with Nomaski optics $(\times 200)$. Embryos were classified according to the following: morulae, compacted embryos that did not contain a blastocoel; early blastocysts, morulae that contained a blastocoel less than $2 / 3$ of the volume of the embryo as determined using an eye-piece graticule; blastocysts, containing a blastocoel at greater than $2 / 3$ of the 


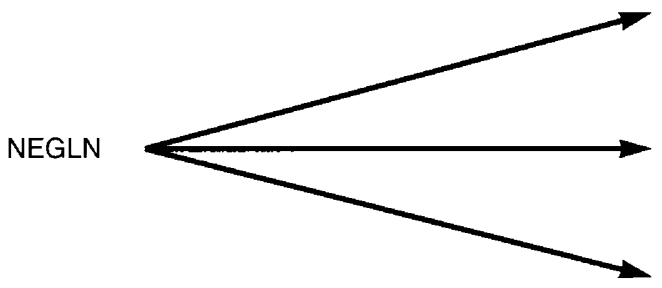

NEGLN

ESS

$20 A A$

ESS

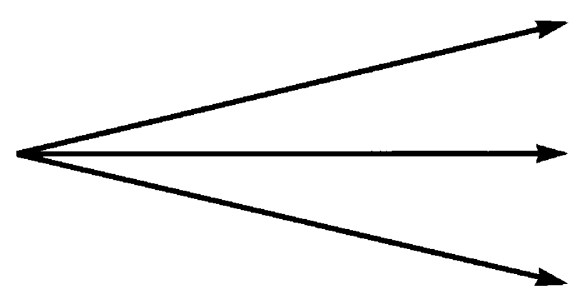

NEGLN

ESS

20AA

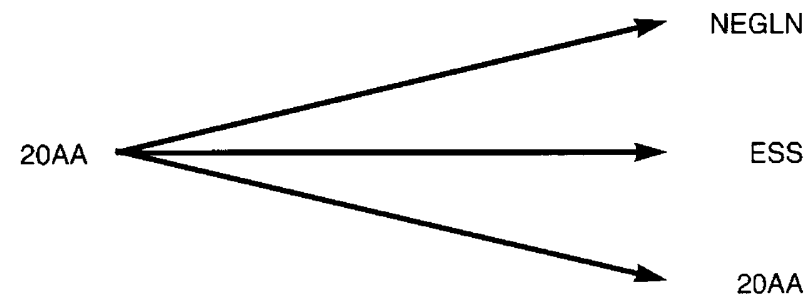

Fig. 1. Amino acid treatments for culture for the first $48 \mathrm{~h}$ before transfer to fresh medium for the second $48 \mathrm{~h}$ of culture. mMTF, mouse tubal fluid medium; NEGLN, mMTF supplemented with non-essential amino acids and glutamine; ESS, mMTF supplemented with essential amino acids without glutamine; 20AA, mMTF supplemented with all 20 amino acids. Medium mMTF was included as a control without amino acids.

total volume of the embryo; hatching blastocysts, blastocysts that have a clear herniation of the zona pellucida by the trophectoderm.

\section{Differential nuclear staining}

The allocation of cells within blastocysts to the inner cell mass (ICM) and trophectoderm (TE) was assessed using a modification of the method of Handyside and Hunter (1984). Blastocysts were incubated in pronase $(0.5 \%(\mathrm{w} / \mathrm{v}))$ for $5-8 \mathrm{~min}$ to remove the zona pellucida, washed in protein-free H-MTF and incubated for $12 \mathrm{~min}$ in I:5 dilution of rabbit anti-mouse serum (ICN Biomedicals) in H-MTF. Blastocysts were subsequently washed in protein-free H-MTF before being incubated for 8 min in 1:10 dilution of complement in H-MTF containing $10 \mu \mathrm{g}$ propidium iodide $\mathrm{ml}^{-1}$. After a brief wash in PBS, blastocysts were placed in $25 \mu \mathrm{g}$ bisbenzimide $\mathrm{ml}^{-1}$ (Hoechst 33258 , Sigma) in ethanol overnight at $4^{\circ} \mathrm{C}$. The following morning embryos were washed in absolute ethanol and mounted in glycerol on a siliconized slide and overlayed with a coverslip. The differential colour of the nuclei were examined under UV light using a Fluovert microscope (Leica, Sydney). Filter block A (excitation wavelength $340-380 \mathrm{~nm}$ ) was used; the nuclei of ICM cells appear blue whilst the TE cell nuclei appear pink. With a green/blue filter (excitation wavelength $350-460 \mathrm{~nm}$ ) only the TE cells are visible. The nuclei were counted after gently applying a small amount of pressure above the embryo to produce a single layered image. Numbers of ICM and TE cells were obtained for each embryo and ratios of ICM:total number of cells calculated for individual embryos.

\section{Blastocyst outgrowth}

After $96 \mathrm{~h}$ of culture, blastocysts were incubated in $200 \mu \mathrm{l}$ drops of medium DMEM (ICN Biomedicals) supplemented with 10\% fetal calf serum (Life Technologies, Melbourne, Australia) in 96 well plates coated with $0.1 \%(\mathrm{w} / \mathrm{v})$ gelatine. Blastocysts were cultured for $48 \mathrm{~h}$ and attachment to the dish and outgrowth of both the ICM and TE cells were assessed. The ability of the cells to proliferate in vitro was assessed using a scoring system (0-3) adapted from Spindle and Pederson (1972). The degree of proliferation of the ICM and TE outgrowths from blastocysts developed in vivo was initially assessed to determine the maximal proliferation rate in vitro. All the blastocysts developed in vivo attached to the dish after $48 \mathrm{~h}$ and the extensive proliferation of both the ICM and TE from blastocysts developed in vivo was rated 3 (extensive outgrowth). No outgrowths was rated 0 , a small degree of outgrowth given a rating of 1 , and a medium degree of outgrowth rated 2 .

\section{Embryo viability}

Blastocyst viability was assessed by transfer to pseudopregnant recipients at day 4 (day of plug was designated day 1 of pregnancy). Recipients were anaesthetized by an i.p. injection of Avertin $\left(0.02 \mathrm{ml} \mathrm{g}^{-1}\right.$ body mass). Surgical transfers conformed with established protocols and had institution ethics approval. Treatments were assigned to each horn by random numbers and six blastocysts transferred to each uterine horn. Implantation sites, fetuses per blastocyst transferred, fetuses per implantation and fetal masses were assessed on day 15 of pregnancy at which time the recipients were killed by cervical dislocation.

\section{Determination of glucose uptake and lactate production}

Glucose uptake and lactate production of individual blastocysts were assessed using non-invasive quantitative microfluorescence (Gardner and Leese, 1990, 1993). Individual blastocysts were incubated in $40 \mathrm{nl}$ drops of medium mMTF modified to contain $0.5 \mathrm{mmol}$ glucose $1^{-1}$ as the sole energy substrate for up to $90 \mathrm{~min}$. Serial $1 \mathrm{nl}$ samples of medium were taken every $30 \mathrm{~min}$ and glucose and lactate concentrations 


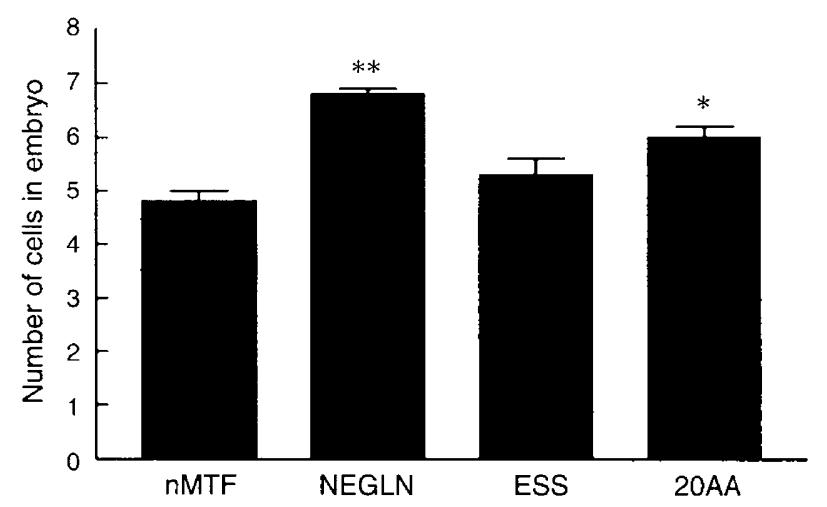

Fig. 2. Effect of amino acids on number of embryo cells of zygotes cultured from the zygote for $48 \mathrm{~h} . n=$ at least 80 embryos per treatment group. mMTF, modified tubal fluid medium; NEGLN, mMTF supplemented with non-essential amino acids and glutamine; ESS, mMTF supplemented with essential amino acids without glutamine; 20AA, mMTF supplemented with all 20 amino acids. *Significantly different from mMTF $(P<0.05)$; ${ }^{*}$ Significantly different from mMTF $(P<0.05)$.

quantitated. Linear rates of glucose uptakes and lactate production were determined for each blastocyst. Glycolytic activity (\%) of individual embryos was calculated on the assumption that 2 moles of lactate are formed from one mole of glucose.

\section{Statistical analysis}

Data were assessed using the assumption of the null hypothesis of no treatment effect against a treatment effect. Data for morphology, implantation and fetal development were analysed using linear-logistic regression assuming a binomial distribution while data for numbers of cells were analysed using log-linear regression where the error distribution was poisson (Nelder and Wedderburn, 1972). Data for glycolytic activity were initially analysed by analysis of variance and between treatment differences determined using Duncan's multiple range test. A probability of at least $P<0.05$ was considered to be statistically significant.

\section{Results}

\section{Morphology}

At the end of the first $48 \mathrm{~h}$ culture period at the time of the changeover into fresh medium there were significant differences in the number of cells of the embryos. Embryos cultured with non-essential amino acids and glutamine $(P<0.01)$ or 20 amino acids $(P<0.05)$ had significantly more cells than did those cultured in the absence of amino acids or essential amino acids without glutamine (Fig. 2). When zygotes were cultured in the various groups of amino acids for a further $48 \mathrm{~h}$ to the blastocyst stage, equivalent rates of blastocysts were formed in all treatments (Table 2). However, the percentage of these blastocysts hatching from the zona pellucida was significantly increased by culture with either non-essential amino acids and glutamine or all 20 amino acids for the second $48 \mathrm{~h}$ culture
Table 2. Effect of amino acids on the development (\%) of zygotes to the blastocyst stage after culture for $96 \mathrm{~h}^{\mathrm{a}}$

\begin{tabular}{llcc}
\hline $\begin{array}{l}\text { 1st } 48 \mathrm{~h}^{\mathrm{b}} \\
\text { culture }\end{array}$ & $\begin{array}{c}\text { 2nd } 48 \mathrm{~h} \\
\text { culture }\end{array}$ & Blastocyst & $\begin{array}{c}\text { Hatching } \\
\text { blastocyst* }\end{array}$ \\
\hline mMTF & mMTF & 85 & $20^{\mathrm{c}}$ \\
NEGLN & NEGLN & 91 & $56^{\mathrm{d}}$ \\
NEGLN & ESS & 86 & $35^{\mathrm{e}}$ \\
NEGLN & 20AA & 91 & $51^{\mathrm{d}}$ \\
ESS & NEGLN & 88 & $62^{\mathrm{d}}$ \\
ESS & ESS & 81 & $27^{\mathrm{c}}$ \\
ESS & 20AA & 92 & $47^{\mathrm{d}}$ \\
$20 \mathrm{AA}$ & NEGLN & 84 & $61^{\mathrm{d}}$ \\
$20 \mathrm{AA}$ & ESS & 79 & $14^{\mathrm{c}}$ \\
$20 \mathrm{AA}$ & $20 \mathrm{AA}$ & 82 & $41^{\mathrm{d}}$ \\
\hline
\end{tabular}

${ }^{a} n=80$ embryos cultured per treatment group.

${ }^{b}$ mMTF, mouse tubal fluid medium; NEGLN, mMTF supplemented with non-essential amino acids and glutamine; ESS, mMTF supplemented with essential amino acids without glutamine; 20AA, mMTF supplemented with all 20 amino acids.

${ }^{c-c}$ Different letters indicate means are significantly different within columns $(P<0.05)$.

*Hatching blastocysts expressed as a percentage of cultured zygotes.

period compared with the control without amino acids (mMTF; $P<0.05)$ or essential amino acids without glutamine $(P<0.05)$ (Table 2).

As there were significant differences in the mean number of cells of embryos after culture from the zygote for $48 \mathrm{~h}$, to avoid bias resulting from embryos being at different stages of development at the start of the second $48 \mathrm{~h}$ culture period (Fig. 2), the effect of amino acids on the development of eight-cell embryos developed in vivo was also determined. The role of glutamine in embryo development was investigated further by examining non-essential and essential amino acid groups with or without glutamine. After $24 \mathrm{~h}$ of culture, eight-cell embryos developed in vivo grown in the presence of non-essential amino acids with or without glutamine or all 20 amino acids had significantly greater blastocyst formation than those grown with mMTF (Table 3). In contrast, culture in the presence of essential amino acids without glutamine for $24 \mathrm{~h}$ significantly reduced the percentage of embryos at the blastocyst stage compared with mMTF $(P<0.05)$ (Table 3). Addition of glutamine to essential amino acids increased blastocyst formation to rates equivalent to mMTF (Table 3).

After a further $24 \mathrm{~h}$ of culture (total of $48 \mathrm{~h}$ of culture) all eight-cell embryos developed in vivo had grown to the blastocyst stage in the six treatment groups. Culture with either non-essential amino acids with or without glutamine or 20 amino acids significantly increased the percentage of blastocysts that were hatching compared with mMTF $(P<0.01)$ (Table 3). Essential amino acids without glutamine did not affect the percentage of hatching blastocysts compared with mMTF (Table 3). However, addition of glutamine to the essential amino acids increased the percentage of hatching blastocysts to the value seen in the other amino acid treatments (Table 3). 
Table 3. Effect of amino acids on the development (\%) of eight-cell embryos developed in vivo to the blastocyst stage ${ }^{a}$

\begin{tabular}{|c|c|c|c|c|c|}
\hline \multirow[b]{2}{*}{ Treatment } & \multicolumn{3}{|c|}{ Culture for $24 \mathrm{~h}$} & \multicolumn{2}{|c|}{ Culture for $48 \mathrm{~h}$} \\
\hline & Morula & $\begin{array}{c}\text { Early } \\
\text { blastocyst }\end{array}$ & Blastocyst & Blastocyst & $\begin{array}{l}\text { Hatching } \\
\text { blastocyst* }\end{array}$ \\
\hline mMTF & 37 & 47 & $16^{\mathrm{b}}$ & 100 & $44^{\mathrm{b}}$ \\
\hline mMTF + non-essential amino acids without glutamine & 25 & 25 & $50^{c}$ & 100 & $75^{\mathrm{c}}$ \\
\hline mMTF + non-essential amino acids with glutamine & 18 & 18 & $65^{\mathrm{c}}$ & 100 & $73^{\mathrm{c}}$ \\
\hline mMTF + essential amino acids without glutamine & II & 89 & $0^{\mathrm{d}}$ & 100 & $52^{\mathrm{b}}$ \\
\hline mMTF + essential amino acids with glutamine & 16 & 63 & $21^{b}$ & 100 & $82^{c}$ \\
\hline $\mathrm{mMTF}+20$ amino acids & 6 & 49 & $45^{c}$ & 100 & $81^{c}$ \\
\hline
\end{tabular}

mMTF, mouse tubal fluid medium.

${ }^{a} n=80$ embryos cultured per treatment group.

${ }^{\mathrm{b}-\mathrm{d}}$ Different letters indicate means are significantly different within columns $(P<0.05)$.

*Hatching blastocysts expressed as a percentage of cultured zygotes.

Table 4. Effects of amino acids on total number of blastocyst cells and cell allocation to the inner cell mass (ICM) and trophectoderm (TE) of zygotes cultured to the blastocyst stage ${ }^{a}$

\begin{tabular}{|c|c|c|c|c|c|}
\hline $\begin{array}{l}\text { Ist } 48 \mathrm{~h}^{\mathrm{b}} \\
\text { culture }\end{array}$ & $\begin{array}{l}\text { 2nd } 48 \mathrm{~h} \\
\text { culture }\end{array}$ & $\begin{array}{c}\text { Total number } \\
\text { of blastocyst } \\
\text { cells }\end{array}$ & $\begin{array}{c}\text { ICM } \\
\text { number } \\
\text { of cells }\end{array}$ & $\begin{array}{c}\text { TE } \\
\text { number } \\
\text { of cells }\end{array}$ & $\begin{array}{c}\text { ICM: total } \\
(\%)\end{array}$ \\
\hline $\mathrm{mMTF}$ & mMTF & $50.6 \pm 1.8^{\mathrm{c}}$ & $5.9 \pm 0.6^{c}$ & $42.1 \pm 1.6^{\mathrm{c}}$ & $12.4 \pm 0.8^{\circ}$ \\
\hline NEGLN & NEGLN & $60.7 \pm 1.1^{d}$ & $7.5 \pm 0.4^{c}$ & $49.7 \pm 1.1^{\mathrm{d}}$ & $12.8 \pm 1.1^{\circ}$ \\
\hline NEGLN & ESS & $66.5 \pm 1.9^{e}$ & $22.6 \pm 1.2^{\mathrm{d}}$ & $43.5 \pm 1.6^{c}$ & $34.8 \pm 1.8$ \\
\hline NEGLN & $20 \mathrm{AA}$ & $67.4 \pm 1.3^{\mathrm{e}}$ & $26.5 \pm 2.1^{d}$ & $40.6 \pm 1.9^{c}$ & $41.5 \pm 2.4^{\circ}$ \\
\hline ESS & NEGLN & $49.2 \pm 2.5^{c}$ & $9.7 \pm 0.9^{c}$ & $39.4 \pm 2.1^{\mathrm{c}}$ & $22.1 \pm 2.2^{e}$ \\
\hline ESS & ESS & $56.7 \pm 1.3^{\mathrm{f}}$ & $20.5 \pm 0.8^{\mathrm{de}}$ & $32.7 \pm 1.6^{\mathrm{e}}$ & $34.8 \pm 1.3^{c}$ \\
\hline ESS & $20 \mathrm{AA}$ & $54.8 \pm 1.9^{c}$ & $17.3 \pm 1.0^{\mathrm{e}}$ & $37.5 \pm 1.7^{c}$ & $33.2 \pm 2.5^{\circ}$ \\
\hline $20 \mathrm{AA}$ & NEGLN & $50.8 \pm 2.9^{c}$ & $14.0 \pm 1.3^{\text {ef }}$ & $35.4 \pm 2.2^{\mathrm{ce}}$ & $25.7 \pm 1.0^{\circ}$ \\
\hline $20 \mathrm{AA}$ & ESS & $56.4 \pm 2.7^{5}$ & $21.8 \pm 1.8^{d}$ & $34.4 \pm 2.8^{c e}$ & $37.9 \pm 1.4^{\circ}$ \\
\hline $20 \mathrm{AA}$ & $20 \mathrm{AA}$ & $58.5 \pm 3.7^{\mathrm{df}}$ & $19.7 \pm 2.2^{\mathrm{df}}$ & $38.7 \pm 2.5^{c}$ & $34.8 \pm 2.1^{\circ}$ \\
\hline In vivo & & $49.7 \pm 1.4$ & $18.6 \pm 1.2$ & $31.8 \pm 1.6$ & $37.7 \pm 1.8$ \\
\hline
\end{tabular}

\footnotetext{
${ }^{a} n=80$ embryos transferred per treatment group.

${ }_{\mathrm{m}}^{\mathrm{mMTF}}$, mouse tubal fluid medium; NEGLN, mMTF supplemented with non-essential amino acids and glutamine; ESS, mMTF supplemented with essential amino acids without glutamine; 20AA, mMTF supplemented with all 20 amino acids.

${ }^{c-f}$ Different letters indicate means are significantly different within columns $(P<0.05)$.
}

\section{Number of cells and allocation to inner cell mass and trophectoderm}

Amino acids present in media used for the culture of zygotes to the blastocyst stage had significant effects on both the total number of cells of the resultant blastocysts and the allocation of cells to the ICM and TE. Blastocysts cultured with nonessential amino acids and glutamine for the first $48 \mathrm{~h}$ had a significantly greater total number of cells compared with culture with either no amino acids $(P<0.05)$ or essential amino acids without glutamine $(P<0.05)$ for the first $48 \mathrm{~h}$ period (Table 4).

Development of the ICM was significantly increased by culture with essential amino acids $(P<0.05)$ or all 20 amino acids $(P<0.05)$ for the second $48 \mathrm{~h}$ compared with mMTF. Moreover, blastocysts cultured with essential amino acids or 20 amino acids had an equivalent percentage of ICM cells to blastocysts developed in vivo collected before implantation ( $24 \mathrm{~h}$ before analysis of cultured blastocysts). In contrast, blastocysts cultured with non-essential amino acids and glutamine for the second $48 \mathrm{~h}$ did not exhibit the same degree of increase in number of ICM cells as did the other amino acid groups (Table 4). Embryos cultured in the presence of nonessential amino acids and glutamine for the entire culture period or in essential amino acids followed by non-essential amino acids and glutamine had equivalent numbers of ICM cells to blastocysts developed in mMTF, that is, in the absence of any amino acids.

The effect of amino acids on number of blastocyst cells and cell allocation of cultured eight-cell embryos developed in vivo was subsequently determined after $48 \mathrm{~h}$ of culture (Table 5). Culture with non-essential amino acids with or without glutamine did not affect the total number of blastocyst cells or allocation to the ICM. Similarly, culture of eight-cell embryos 
Table 5. Effect of amino acids on number of blastocyst cells and allocation to the inner cell mass (ICM) and trophectoderm (TE) in in vivo developed eight-cell embryos cultured for $48 \mathrm{~h}$ to the blastocyst stage ${ }^{\mathrm{a}}$

\begin{tabular}{lcccc}
\hline Treatment & $\begin{array}{c}\text { Total number } \\
\text { of cells in } \\
\text { blastocyst } \\
\text { (mean } \pm \text { SEM) }\end{array}$ & $\begin{array}{c}\text { ICM } \\
\text { number of } \\
\text { cells } \\
\text { (mean } \pm \text { SEM) }\end{array}$ & $\begin{array}{c}\text { TE } \\
\text { number of } \\
\text { cells } \\
\text { (mean } \pm \text { SEM) }\end{array}$ & $\begin{array}{c}\text { ICM:total } \\
\text { number of } \\
\text { cells } \\
(\%)\end{array}$ \\
\hline mMTF & $73.5 \pm 3.5^{\mathrm{b}}$ & $16.8 \pm 1.3^{\mathrm{b}}$ & $58.4 \pm 3.2^{\mathrm{b}}$ & $23.4 \pm 1.7^{\mathrm{b}}$ \\
mMTF + non-essential amino acids without glutamine & $75.3 \pm 4.7^{\mathrm{b}}$ & $25.5 \pm 5.0^{\mathrm{b}}$ & $49.8 \pm 5.3^{\mathrm{b}}$ & $42.1 \pm 3.5^{\mathrm{c}}$ \\
mMTF + non-essential amino acids with glutamine & $78.7 \pm 3.8^{\mathrm{b}}$ & $24.5 \pm 3.2^{\mathrm{b}}$ & $53.5 \pm 3.6^{\mathrm{b}}$ & $43.8 \pm 4.7^{\mathrm{c}}$ \\
mMTF + essential amino acids without glutamine & $76.7 \pm 5.4^{\mathrm{b}}$ & $39.9 \pm 5.3^{\mathrm{c}}$ & $36.9 \pm 5.5^{\mathrm{b}}$ & $40.9 \pm 7.8^{\mathrm{c}}$ \\
mMTF + essential amino acids with glutamine & $97.6 \pm 4.4^{\mathrm{c}}$ & $45.3 \pm 4.0^{\mathrm{c}}$ & $53.2 \pm 1.6^{\mathrm{b}}$ & $47.7 \pm 4.2^{\mathrm{c}}$ \\
mMTF + 20 amino acids & $93.1 \pm 3.6^{\mathrm{c}}$ & $38.6 \pm 4.1^{\mathrm{c}}$ & $54.4 \pm 3.2^{\mathrm{b}}$ & $54.1 \pm 2.0^{\mathrm{c}}$ \\
\hline
\end{tabular}

mMTF, mouse tubal fluid medium.

${ }^{a} n=80$ embryos cultured per treatment group.

${ }^{b-d}$ Different letters indicate means are significantly different within columns $(P<0.05)$.

with essential amino acids without glutamine did not affect the total number of blastocyst cells compared with mMTF (Table 5). However, essential amino acids with glutamine $(P<0.01)$ and all 20 amino acids $(P<0.01)$ significantly increased the total number of blastocyst cells compared with blastocysts cultured in MMTF and all other treatments. Culture of eight-cell embryos in the presence of essential amino acids with or without glutamine or all 20 amino acids significantly increased both the number of ICM cells in resultant blastocysts $(P<0.05)$ and the percentage of ICM:total cell number $(P<0.05)$ (Table 5). Culture with non-essential amino acids with or without glutamine had no significant effect on ICM development although the ratio of ICM:total cell number was higher (Table 5).

\section{Outgrowth on ICM and TE cells in vitro}

Culture with non-essential amino acids and glutamine for the second $48 \mathrm{~h}$ culture period did not affect the outgrowth ability of either the ICM or TE cells compared with blastocysts developed in mMTF. In contrast, culture with essential amino acids without glutamine or all 20 amino acids for the second $48 \mathrm{~h}$ significantly increased the ability of both the TE and ICM cells to proliferate in vitro (Table 6).

\section{Effect of amino acids on embryo viability}

Implantation rates of cultured blastocysts were significantly increased by the presence of non-essential amino acids and glutamine in the medium for the first $48 \mathrm{~h}$ culture period $(P<0.01)$ (Table 7). The highest implantation rate was observed when zygotes were cultured with non-essential amino acids and glutamine for the first $48 \mathrm{~h}$ and then all 20 amino acids for the second $48 \mathrm{~h}$ culture period and was not different to the in vivo derived controls collected $24 \mathrm{~h}$ earlier before implantation (Table 7).

Similarly, fetal development per blastocyst transferred was also increased by culture with non-essential amino acids and glutamine for the first $48 \mathrm{~h}$ compared with either essential
Table 6. Effect of amino acids during zygote development to the blastocyst stage on attachment and outgrowth in vitro ${ }^{a}$

\begin{tabular}{llccc}
\hline $\begin{array}{l}\text { 1st } 48 \mathrm{~h}^{\mathrm{b}} \\
\text { culture }\end{array}$ & $\begin{array}{c}\text { 2nd } 48 \mathrm{~h} \\
\text { culture }\end{array}$ & $\begin{array}{c}\text { Attachment } \\
(\%)\end{array}$ & $\begin{array}{c}\text { ICM } \\
\text { outgrowth } \\
(\text { mean } \pm \text { SEM })\end{array}$ & $\begin{array}{c}\text { TE } \\
\text { outgrowth } \\
\text { (mean } \pm \text { sEM) }\end{array}$ \\
\hline mMTF & mMTF & $52^{\mathrm{c}}$ & $1.1 \pm 0.2^{\mathrm{c}}$ & $1.1 \pm 0.1^{\mathrm{c}}$ \\
NEGLN & NEGLN & $56^{\mathrm{c}}$ & $1.6 \pm 0.2^{\mathrm{d}}$ & $1.0 \pm 0.2^{\mathrm{c}}$ \\
NEGLN & ESS & $86^{\mathrm{d}}$ & $2.5 \pm 0.1^{\mathrm{e}}$ & $2.9 \pm 0.2^{\mathrm{d}}$ \\
NEGLN & 20AA & $88^{\mathrm{d}}$ & $2.4 \pm 0.3^{\mathrm{e}}$ & $2.6 \pm 0.3^{\mathrm{d}}$ \\
ESS & NEGLN & $43^{\mathrm{c}}$ & $0.7 \pm 0.2^{\mathrm{c}}$ & $2.0 \pm 0.1^{\mathrm{c}}$ \\
ESS & ESS & $100^{\mathrm{d}}$ & $2.7 \pm 0.3^{\mathrm{e}}$ & $2.9 \pm 0.1^{\mathrm{d}}$ \\
ESS & 20AA & $67^{\mathrm{c}}$ & $1.8 \pm 0.4^{\mathrm{d}}$ & $1.8 \pm 0.3^{\mathrm{e}}$ \\
20AA & NEGLN & $50^{\mathrm{c}}$ & $0.8 \pm 0.3^{\mathrm{c}}$ & $1.8 \pm 0.4^{\mathrm{e}}$ \\
$20 \mathrm{AA}$ & ESS & $50^{\mathrm{c}}$ & $2.0 \pm 0.3^{\mathrm{d}}$ & $2.0 \pm 0.3^{\mathrm{e}}$ \\
20AA & 20AA & $100^{\mathrm{d}}$ & $2.0 \pm 0.4^{\mathrm{d}}$ & $2.0 \pm 0.2^{\mathrm{c}}$ \\
\hline
\end{tabular}

ICM, inner cell cell mass; $\mathrm{TE}$, trophectoderm.

${ }^{a} n=80$ embryos transferred per treatment group.

bmMTF, mouse, tubal fluid medium; NEGLN, mMTF supplemented with non-essential amino acids and glutamine; ESS, mMTF supplemented with essential amino acids without glutamine; 20AA, mMTF supplemented with all 20 amino acids.

${ }^{c-e}$ Different letters indicate means are significantly different within columns $(P<0.05)$

amino acids without glutamine $(P<0.05)$ or all 20 amino acids $(P<0.05)$. However, culture with non-essential amino acids for the second $48 \mathrm{~h}$ did not affect fetal development. In contrast, culture with essential amino acids without glutamine or all 20 amino acids from the eight-cell to the blastocyst stage significantly increased both fetal development per blastocyst transferred $(P<0.05)$ and fetal mass $(P<0.05)$.

\section{Glucose uptake and lactate production}

Blastocysts cultured in the presence of amino acids took up significantly more glucose than did those cultured with no amino acids (Table 8). Glucose uptake of blastocysts was 
Table 7. Effect of amino acids on embryo viability of zygotes cultured to the blastocyst stage ${ }^{a}$

\begin{tabular}{|c|c|c|c|c|c|}
\hline $\begin{array}{l}\text { Ist } 48 \mathrm{~h}^{\mathrm{b}} \\
\text { culture }\end{array}$ & $\begin{array}{l}\text { 2nd } 48 \mathrm{~h} \\
\text { culture }\end{array}$ & $\begin{array}{c}\text { Implantation/ } \\
\text { transfer } \\
(\%)\end{array}$ & $\begin{array}{c}\text { Fetuses/ } \\
\text { blastocyst } \\
\text { transfered } \\
(\%)\end{array}$ & $\begin{array}{c}\text { Fetuses/ } \\
\text { implantation } \\
(\%)\end{array}$ & $\begin{array}{c}\text { Fetal } \\
\text { mass }(\mathrm{mg}) \\
(\text { mean } \pm \mathrm{SEM})\end{array}$ \\
\hline mMTF & mMTF & $44^{c}$ & $21^{c}$ & 48 & $194 \pm 11^{c}$ \\
\hline NEGLN & NEGLN & $67^{\mathrm{d}}$ & $29^{d}$ & 44 & $209 \pm 14^{c}$ \\
\hline NEGLN & ESS & $64^{d}$ & $50^{e}$ & 78 & $244 \pm 8^{d}$ \\
\hline NEGLN & $20 \mathrm{AA}$ & $92^{\mathrm{e}}$ & $54^{\mathrm{e}}$ & 58 & $232 \pm 10^{\mathrm{d}}$ \\
\hline ESS & NEGLN & $48^{c}$ & $10^{c}$ & 20 & $178 \pm 13^{c}$ \\
\hline ESS & ESS & $61^{\mathrm{cd}}$ & $39^{f}$ & 64 & $218 \pm 9^{d}$ \\
\hline ESS & $20 \mathrm{AA}$ & $56^{\mathrm{c}}$ & $22^{d}$ & 40 & $197 \pm 5^{c}$ \\
\hline $20 \mathrm{AA}$ & NEGLN & $40^{c}$ & $13^{\mathrm{c}}$ & 33 & $147 \pm 15^{\mathrm{e}}$ \\
\hline $20 \mathrm{AA}$ & ESS & $54^{\mathrm{c}}$ & $25^{\mathrm{d}}$ & 46 & $201 \pm 19^{\circ}$ \\
\hline $20 \mathrm{AA}$ & $20 \mathrm{AA}$ & $68^{d}$ & $38^{d}$ & 56 & $229 \pm 9^{d}$ \\
\hline In vivo & & $92^{\mathrm{e}}$ & $70^{* *}$ & 76 & $307 \pm 12^{* *}$ \\
\hline
\end{tabular}

${ }_{n}=80$ embryos transferred per treatment group.

${ }^{b}$ mMTF, mouse tubal fluid medium; NEGLN, mMTF supplemented with non-essential amino acids and glutamine; ESS, mMTF supplemented with essential amino acids without glutamine; 20AA, mMTF supplemented with all 20 amino acids.

${ }^{c-}$ Different letters indicate means are significantly different within columns $(P<0.05)$.

${ }^{* *}$ Significantly different from all other treatments within columns $(P<0.01)$.

Table 8. Effect of amino acids on glycolytic activity of cultured blastocysts ${ }^{a}$

\begin{tabular}{llccc}
\hline $\begin{array}{l}1 \text { st } 48 \mathrm{~h}^{\mathrm{b}} \\
\text { culture }\end{array}$ & $\begin{array}{c}\text { 2nd } 48 \mathrm{~h} \\
\text { culture }\end{array}$ & $\begin{array}{c}\text { Glucose uptake } \\
\text { (pmol per embryo } \mathrm{h}^{-1} \text { ) } \\
\text { (mean } \pm \text { SEM) }\end{array}$ & $\begin{array}{c}\text { Lactate production } \\
\left(\text { pmol per embryo } \mathrm{h}^{-1} \text { ) }\right. \\
\text { (mean } \pm \text { SEM) }\end{array}$ & $\begin{array}{c}\text { Glycolysis } \\
(\%) \\
\text { (mean } \pm \text { SEM) }\end{array}$ \\
\hline mMTF & mMTF & $5.12 \pm 0.47^{*}$ & $10.62 \pm 1.74^{*}$ & $107.5 \pm 6.9^{\mathrm{c}}$ \\
NEGLN & NEGLN & $6.80 \pm 0.68^{\mathrm{c}}$ & $17.74 \pm 1.60$ & $135.1 \pm 11.0^{\mathrm{d}}$ \\
NEGLN & 20AA & $9.81 \pm 0.99^{\mathrm{d}}$ & $16.94 \pm 1.46$ & $99.0 \pm 8.2^{\mathrm{c}}$ \\
ESS & NEGLN & $7.21 \pm 0.96^{\mathrm{c}}$ & $20.51 \pm 3.51$ & $151.8 \pm 25.7^{\mathrm{d}}$ \\
ESS & ESS & $10.63 \pm 0.48^{\mathrm{d}}$ & $16.94 \pm 1.46$ & $86.5 \pm 6.9^{\mathrm{c}}$ \\
$20 \mathrm{AA}$ & 2OAA & $8.63 \pm 0.78^{\mathrm{c}}$ & $16.32 \pm 1.20$ & $101.2 \pm 7.8^{\mathrm{c}}$ \\
\hline
\end{tabular}

$a_{n}=$ at least 10 embryos per treatment group.

${ }^{b}$ mMTF, mouse tubal fluid medium; NEGLN, mMTF supplemented with non-essential amino acids and glutamine; ESS, mMTF supplemented with essential amino acids without glutamine; 20AA, mMTF supplemented with all 20 amino acids.

${ }^{c-e}$ Different letters indicate means are significantly different within columns $(P<0.05)$.

*Significantly different from all other treatments within columns $(P<0.05)$.

significantly increased by culture with essential amino acids for the second $48 \mathrm{~h}$ compared to non-essential amino acids and glutamine. Embryos cultured with non-essential amino acids and glutamine for the second $48 \mathrm{~h}$ period had significantly lower glucose uptake compared with embryos cultured in essential amino acids. Lactate production by blastocysts was increased by culture with amino acids compared with mMTF $(P<0.05)$. However, changing the amino acid composition of the medium did not affect lactate production. In contrast, glycolytic rate, or percentage of glucose converted to lactate, was significantly affected by the amino acids in the culture medium. Blastocysts cultured with non-essential amino acids and glutamine had a glycolytic rate above $100 \%$. Blastocysts cultured with 20 amino acids had a mean glycolytic activity of around $100 \%$ whilst blastocysts cultured with essential amino acids had a glycolytic activity less than 100\% (Table 8).

\section{Correlations}

The various parameters of embryo development in vitro quantitated in this study were correlated with fetal development after transfer of cultured blastocysts (Fig. 3). Morphology as assessed by blastocyst formation (Fig. 3a) and hatching (Fig. 3b) were not correlated with subsequent developmental competence. In contrast, there was a significant positive correlation between number of blastocyst cells (Fig. 3c) and number of ICM cells (Fig. 3d) and subsequent fetal development $(P<0.01)$. The number of TE cells in the blastocysts was not correlated with fetal development (Fig. 3e). Similarly the ability of blastocysts to attach and ICM outgrowth were also positively correlated with fetal development $(P<0.01)$ (Fig. 3f). Glycolytic activity of blastocysts appeared to be negatively correlated with fetal development after transfer $(P<0.07)$ (Fig. 3g). 

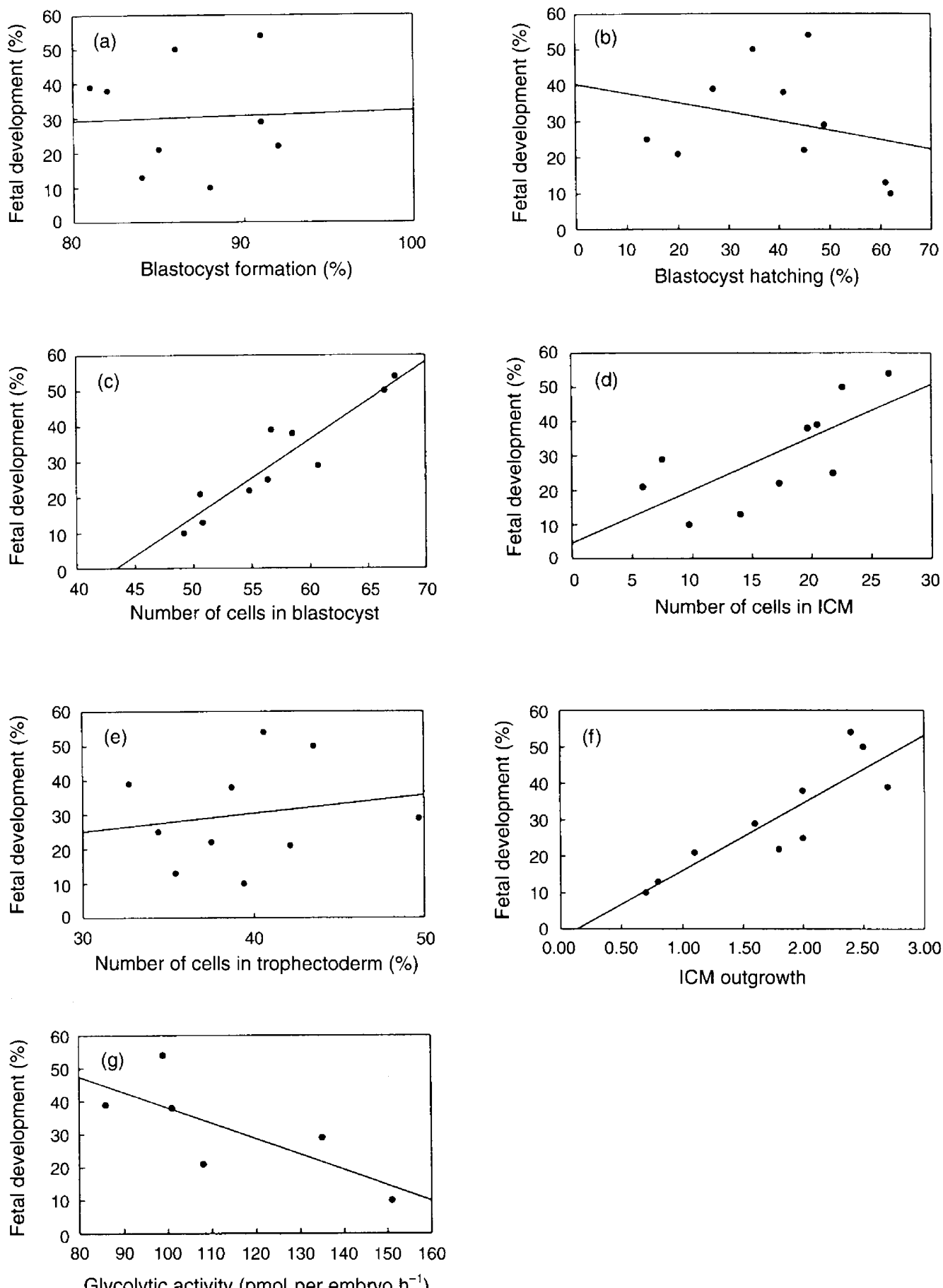

Fig. 3. Correlations between parameters for embryo assessment and fetal development after transfer. (a) Blastocyst formation and fetal development $(P>0.1)$; (b) blastocyst hatching and fetal development $(P>0.1)$; (c) total number of cells in blastocyst and fetal development $(P<0.01)$; (d) number of cells in inner cell mass and fetal development $(P<0.05)$; (e) number of cells in trophectoderm and fetal development $(P>0.1)$; (f) outgrowth of inner cell mass in vitro and fetal development $(P<0.01)$; $(\mathrm{g})$ glycolytic activity and fetal development $(P<0.07)$.

\section{Discussion}

This study has demonstrated that the amino acid requirement of preimplantation mouse embryos changes as development proceeds from the zygote to the blastocyst stage. Initially,
Eagle's non-essential amino acids and glutamine stimulated cleavage of zygotes to the eight-cell stage. The presence of Eagle's essential amino acids without glutamine in the culture medium for the first $48 \mathrm{~h}$ of culture conferred no benefit to the embryo. After the eight-cell stage, culture with non-essential 
amino acids and glutamine no longer affected cleavage or development of the ICM; however, they did stimulate blastocoel formation and blastocyst hatching. In contrast to their lack of effect on the embryo during the first four cell cycles, culture with essential amino acids from the eight-cell stage to the blastocyst stimulated cleavage, development of the ICM and fetal development after transfer. Development in vitro and subsequent implantation and fetal development rates were subsequently highest when zygotes were cultured in the presence of non-essential amino acids and glutamine for $48 \mathrm{~h}$ followed by development to the blastocyst stage in the presence of all 20 amino acids. Analysis of development in vitro and subsequent viability revealed that blastocyst formation and hatching was not related to subsequent developmental competence after transfer. In contrast, development of the ICM was positively correlated with subsequent viability whilst glycolytic activity appeared to be inversely correlated with viability. Rates of blastocyst formation and hatching were poor indicators of the suitability of media to maintain embryo viability in vitro and as such are not useful criteria for the assessment of embryo development in different culture systems.

Previously we have shown that the culture of mouse zygotes for $48 \mathrm{~h}$ with Eagle's non-essential amino acids and glutamine significantly increased implantation and fetal development rates after transfer, while culture of zygotes with essential amino acids without glutamine to the six- to eight-cell stage significantly reduced fetal masses after transfer (Lane and Gardner, 1994). In this study culture for the first $48 \mathrm{~h}$ with non-essential amino acids and glutamine significantly increased cleavage to the eight-cell stage as well as significantly increasing subsequent number of blastocyst cells and fetal development independent of the amino acids present in the medium for the second $48 \mathrm{~h}$ of culture. Essential amino acids without glutamine at the concentrations in Eagle's medium did not confer their beneficial effects in vitro during the first four cell cycles.

It has previously been reported that culture of mouse zygotes with non-essential amino acids and glutamine significantly increases both blastocyst formation after $72 \mathrm{~h}$ of culture and resultant number of blastocyst cells compared with embryos cultured without amino acids (Gardner and Lane, 1993b). In this study as well as stimulating development of the cleavage stage embryo, non-essential amino acids stimulated blastocoel formation and expansion as well as increasing the hatching rates of resultant blastocysts. However, culture with non-essential amino acids from the eight-cell to the blastocyst stage did not stimulate cleavage, ICM development or fetal development. It would appear therefore that the previously reported increase in number of blastocyst cells is due solely to the stimulation of cleavage up to the eight-cell stage.

In contrast to non-essential amino acids, culture with essential amino acids without glutamine from the eight-cell stage to the blastocyst significantly increased cleavage rates, ICM development, fetal development and fetal masses after transfer. A similar effect of essential amino acids has been reported for rats, in which eight-cell embryos cultured to the blastocyst stage with essential amino acids resulted in increased fetal development after transfer (Zhang and Armstrong, 1990). However, essential amino acids have previously been observed to inhibit the number of mouse zygote cells cultured to the blastocyst stage (Gardner and Lane, 1993b). It is possible that these reported inhibitory effects of essential amino acids on mouse embryo development are confined to the early cleavage stage embryo. Furthermore, hamster zygote development to the blastocyst stage is also inhibited by the essential amino acids arginine, cysteine, isoleucine, leucine, methionine, phenylalanine, threonine, tyrosine and valine (Bavister and Arlotto, 1990). It is possible that this inhibition of these essential amino acids is also confined to the cleavage stage embryo. In contrast to the early stage embryo, mouse blastocyst attachment and outgrowth is increased by the presence of the essential amino acids lysine, methionine, phenylalanine, threonine, tryptophan, tyrosine valine and glutamine in the culture medium (Spindle and Pederson, 1972). Consistent with this, proliferation of ICM and TE cells of cultured blastocyst in vitro in this study was increased by exposure to essential amino acids during the second $48 \mathrm{~h}$ of culture. Analysis of amino acid uptake by blastocysts between day 4 and day 5 of development in culture (Lamb and Leese, 1994) showed that there was a $170 \%$ increase in the uptake of essential amino acids from the medium, while the uptake of the non-essential amino acids increased by $30 \%$. Uptake of both non-essential amino acids and essential amino acids at the blastocyst stage suggests that they have a role in peri-implantation embryo development. In support of this, the highest rates of cleavage, ICM development and fetal development were observed when embryos were cultured in the presence of all 20 amino acids from the eight-cell stage to the blastocyst stage.

This switch in amino acid requirements by the preimplantation embryo may be reflected in the differing roles of these amino acids. As the early embryo before compaction is dependent on the surrounding environment for the supply of nutrients (Miller and Schultz, 1987; Gardner and Leese, 1990), regulation of $\mathrm{pH}_{\mathrm{i}}$ (Bavister and McKiernan, 1993) and osmolarity (Van Winkle et al., 1990), non-essential amino acids and glutamine may stimulate the cleavage stage embryo by both their protective functions and as oxidative energy sources. In contrast to the non-essential amino acids, essential amino acids without glutamine did not stimulate preimplantation embryo development during the first $48 \mathrm{~h}$ of culture. As Eagle's essential amino acids are defined as those amino acids required for the maintenance of somatic cells in vitro (Eagle, 1959), the embryo may not utilize these amino acids until blastomeres develop a more somatic cell-like physiology after compaction. Furthermore, protein synthetic activity by the cleavage stage embryo is initially low, increasing significantly at the blastocyst stage. The later stage embryo may therefore require essential amino acids to ensure adequate protein synthesis (Monesi and Salfi, 1967).

The detrimental effect of essential amino acids on the cleavage stage embryo is somewhat surprising as they are present in the female reproductive tract, albeit at lower concentrations than those present in the non-essential group (Menezo, 1972; Miller and Schultz, 1987; Gardner and Lane, 1993b). However, essential amino acids other than threonine make up only $15 \%$ of the amino acids in oviduct fluid (Miller and Schultz 1987; Gardner and Lane, 1993b). Therefore many of the essential amino acids in Eagle's medium (Eagle 1959) are present at concentrations higher than the embryo would be exposed to in vivo, resulting in a net negative effect on the 
embryo. Hamster zygote development to the blastocyst stage is inhibited by the essential amino acids cysteine and lysine at a concentration of $0.5 \mathrm{mmol}^{-1}$, while the same amino acids stimulate development at a concentration of $0.05 \mathrm{mmol} \mathrm{l}^{-1}$ (Bavister and McKiernan, 1993). Therefore, an explanation for the detrimental effect by essential amino acids is that one or more may be inhibitory at the concentration in Eagle's formulation and thereby masks the beneficial effects of the other amino acids. In support of this hypothesis is the finding that the inhibitory effect of the MEM vitamins on mouse embryo development in culture in the absence of amino acids was attributed to one vitamin, nicotinamide (Tsai and Gardner, 1994). The stimulatory effects of a second vitamin riboflavin were suppressed in the presence of nicotinamide. Alternatively, the negation of the beneficial effects of non-essential amino acids by the essential amino acids during the first four cell cycles could be attributed to competition for transport systems (Van Winkle, 1988; Van Winkle et al., 1992).

The result presented in this study shows that glutamine has an important role in blastocyst development. In the presence of non-essential amino acids, glutamine had no effect on eight-cell development to the blastocyst stage, blastocyst cell number or allocation to the ICM. In contrast, supplementation of essential amino acids with glutamine increases blastocyst formation and hatching and increased number of blastocyst cells. This increase was entirely attributable to an increase in TE cells. It has previously been shown that the addition of glutamine to the culture medium as the sole amino acid increases development beyond the two-cell block in mice as well as stimulating subsequent development to the blastocyst stage in mice (Chatot et al., 1989) and hamsters (Carney and Bavister, 1987; McKiernan et al., 1991). Glutamine is both taken up and metabolized by preimplantation embryos (Gardner et al., 1989; Chatot et al., 1990; Rieger et al., 1992). That glutamine does not stimulate embryo development in vitro in the presence of non-essential amino acids indicates a degree of plasticity by the developing embryo regarding its use of amino acids. Indeed development beyond the two-cell block and subsequent blastocyst formation of mouse embryos from a blocking strain (CFI) in vitro is equivalent in the presence of non-essential amino acids with or without glutamine (Gardner and Lane, 1996). It would appear that the preimplantation embryo can utilize an alternative amino acid(s) in the non-essential group in preference to glutamine. The non-essential amino acids alanine, glutamate and serine may also be utilized as an energy source by the developing embryo. Indeed the concentrations of alanine and glutamate in oviduct fluid are around 2-4 times higher than that of glutamine (Perkins and Goode, 1967; Menezo, 1972; Miller and Schultz, 1987; Gardner and Leese, 1990). Therefore it appears probable that the preimplantation embryo utilizes glutamine in the absence of alanine and glutamate (when cultured with essential amino acids); however, the embryo may utilize alanine and glutamate preferentially instead of glutamine (when cultured with non-essential amino acids).

Amino acids in the culture medium were shown to affect the activity of glycolysis in the blastocyst. Although all the amino acid groups stimulated glucose uptake at the blastocyst stage, the effect on the resultant metabolism of glucose was markedly different. Blastocysts cultured with non-essential amino acids and glutamine during the second $48 \mathrm{~h}$ exhibited abnormally high levels of glycolysis. It is not feasible that intracellular pools of amino acids of the blastocyst could maintain such high lactate production over the $90 \mathrm{~min}$ of measurement. Furthermore, as the metabolic measurements in this study were performed in medium devoid of amino acids, any intracellular amino acids will rapidly efflux from the cell down its concentration gradient. Therefore, the observed high lactate production suggests that these embryos may be utilising endogenous energy supplies that are required at the time of implantation. In contrast to non-essential amino acids and glutamine, culture with essential amino acids without glutamine for the second $48 \mathrm{~h}$ resulted in blastocysts with a glycolytic activity of less than $100 \%$. These blastocysts may therefore maintain their energy requirements without needing to utilize endogenous carbohydrate energy stores. The ability to maintain energy production utilising exogenous substrates is important as levels of glycolytic activity of blastocysts produced in this study were inversely correlated with subsequent ability to form a fetus. Indeed it has been shown that glycolytic activity can be used as a prospective marker of viable culture blastocysts before transfer (Lane and Gardner, 1996). Those blastocysts having a glycolytic activity greater than or similar to that observed in vivo (around $40 \%$ ) have an $80 \%$ fetal development rate, while those blastocysts whose glycolytic activity is greater than $100 \%$ have a significantly reduced developmental potential (Lane and Gardner, 1996). It is of interest that glucose uptake by blastocysts was increased by culture with amino acids. Glucose uptake and subsequent viability are related in both the mouse (Gardner and Leese, 1987) and cow (Renard et al., 1980) blastocyst. Fetal development after transfer was also found to be positively correlated with total number of cells, specifically with development of the ICM in blastocyst. As the ICM cells of the blastocyst are the sole cellular source of the resultant fetus (Gardner and Papaioannou, 1975), it is perhaps not surprising that the development of the ICM is correlated with fetal development. The identification of such in vitro markers of subsequent developmental competence has implications for the assessment of embryo viability in culture where embryo transfers are impractical such as in domestic animals and endangered species.

In conclusion, the preimplantation mouse embryo undergoes a switch in amino acid requirements after the eight-cell stage. Optimal development in vitro and in vivo after transfer occurs when cleavage stage embryos were cultured with non-essential amino acids and glutamine for $48 \mathrm{~h}$ followed by development to the blastocyst stage with all 20 amino acids. It is proposed therefore that culture systems for the development of preimplantation embryos in vitro will require at least two media to reflect the changes in both carbohydrate and nitrogen requirements of the embryo. Consistent with this proposal are the observed changes in carbohydrate requirements and metabolism around the time of compaction (Biggers et al., 1989). Furthermore, this study has demonstrated that rates of blastocyst formation and hatching are not indicative of the ability of a culture system to maintain embryo viability in vitro. However, developmental competence after transfer is correlated with number of blastocyst cells and ICM development, and appears to be inversely related to glycolytic activity. Therefore when assessing the suitability of preimplantation embryo culture systems a least one of the latter parameters should be used. 
M. Lane was supported by a Studentship from the Australian NH\&MRC. D. K. Gardner was supported by a Fellowship from the Australian Research Council.

\section{References}

Bavister BD (1987) Studies on the developmental blocks in cultured hamster embryos. In The Mammalian Preimplantation Embryo pp 219-249 Ed. BD Bavister. Plenum Press, New York

Bavister BD (1995) Culture of preimplantation embryos: facts and artifacts Human Reproduction Update 1 91-148

Bavister BD and Arlotto T (1990) Influence of single amino acids on the development of hamster one-cell embryos in vitro. Molecular Reproduction and Development 25 45-51

Bavister BD and McKiernan SH (1993) Regulation of hamster embryo development in vitro by amino acids. In Preimplantation Embryo Development pp 57-72 Ed. BD Bavister. Plenum Press, New York

Biggers JD, Gardner DK and Leese HJ (1989) Control of carbohydrate metabolism in preimplantation mammalian embryos. In Growth Factors in Mammalian Development pp 19-32 Eds IY Rosenblum and S Heyner. CRC Press, Boca Raton

Bowman P and McLaren A (1970a) Cleavage rate of mouse embryos in vivo and in vitro. Journal of Embryology and Experimental Morphology 24 203-207

Bowman P and McLaren A (1970b) Viability and growth of mouse embryos after in vivo culture and fusion Journal of Embryology and Experimental Morphology 23 693-704

Carney EW and Bavister BD (1987) Stimulatory and inhibitory effects of amino acids on the development of hamster eight-cell embryos in vitro Journal of In Vitro Fertilization and Embryo Transfer 4 162-167

Chatot CL, Ziomek CA, Bavister BD, Lewis JL and Torres I (1989) An improved culture medium supports development of random-bred 1-cell mouse embryos in vitro. Journal of Reproduction and Fertility 86 679-688

Chatot CL, Tasca RJ and Ziomek CA (1990) Glutamine uptake and utilization by preimplantation mouse embryos in $\mathrm{CZB}$ medium Journal of Reproduction and Fertility $89335-346$

Eagle H (1959) Amino acid metabolism in mammalian cell cultures Science 130 $432-437$

Gardner DK (1994) Mammalian embryo culture in the absence of serum or somatic cell support Cell Biology International 18 1163-1179

Gardner DK and Lane M (1993a) Embryo culture systems. In Handbook of in Vitro Fertilization pp 85-114 Eds AO Trounson and DK Gardner. CRC Press, Boca Raton

Gardner DK and Lane M (1993b) Amino acids and ammonium regulate the development of preimplantation mouse embryos in culture Biology of Reproduction 48 377-385

Gardner DK and Lane M (1996) Alleviation of the "2-cell block" and development to the blastocyst of CF1 mouse embryos: role of amino acids, EDTA and physical parameters Human Reproduction 11 2703-2712

Gardner DK and Leese HJ (1987) Assessment of embryo viability prior to transfer by the non-invasive measurement of glucose uptake Journal of Experimental Zoology 242 103-105

Gardner DK and Leese HJ (1990) Concentrations of nutrients in mouse oviduct fluid and their effects on embryo development and metabolism in vitro Journal of Reproduction and Fertility 88 361-368

Gardner DK and Leese HJ (1993) Assessment of embryo metabolism and viability. In Handbook of In Vitro Fertilization pp 195-211. Eds AO Trounson and DK Gardner. CRC Press, Boca Raton

Gardner DK, Clarke RN, Lechene CP and Biggers JD (1989) Development of a noninvasive ultramicrofluorometric method for measuring net uptake of glutamine by single mouse preimplantation embryos Gamete Research 24 $427-438$

Gardner DK, Lane M, Spitzer A and Batt PA (1994) Enhanced rates of cleavage and development for sheep zygotes cultured to the blastocyst stage in vitro in the absence of serum and somatic cells: amino acids, vitamins and culturing embryos in groups stimulate development Biology of Reproduction 50 390-400

Gardner RL and Papaioannou VE (1975) Differentiation in the trophectoderm and inner cell mass. In The Early Developmental of Mammals pp 107-132 Eds ME Balls and AE Wild. Cambridge University Press, Cambridge

Handyside AH and Hunter S (1984) A rapid procedure for visualising the inner cell mass and trophectoderm nuclei of mouse blastocysts in situ using polynucleotide- specific fluorochromes Journal of Experimental Zoology 231 429-434

Ho Y, Wigglesworth K, Eppig JJ and Schultz RM (1995) Preimplantation development of mouse embryos in KSOM: augmentation by amino acids and analysis of gene expression Molecular Reproduction and Development 41 $232-238$

Lamb V and Leese HJ (1994) Uptake of a mixture of amino acids by mouse blastocysts Journal of Reproduction and Fertility 102 169-175

Lane M and Gardner DK (1992) Effect of incubation volume and embryo density on the development and viability of preimplantation mouse embryos in vitro. Human Reproduction 7 558-562

Lane M and Gardner DK (1994) Increase in post-implantation development of cultured mouse embryos by amino acids and induction of fetal retardation and exencephaly by ammonium ions Journal of Reproduction and Fertility $\mathbf{1 0 2}$ 305-312

Lane M and Gardner DK (1996) Selection of viable blastocysts prior to transfer using a metabolic criterion Human Reproduction II 1975-I978

McKiernan SH, Bavister BD and Tasca RJ (1991) Energy substrate requirements for in vitro development of hamster 1-and 2-cell embryos to the blastocyst stage Human Reproduction 6 64-75

Mehta TS and Kiessling AA (1990) Development potential of mouse embryos conceived in vitro and cultured in ethylenediaminetetraacetic acid with or without amino acids or serum Biology of Reproduction 43 600-606

Menezo YJR (1972) Amino constituents of tubal and uterine fluids of the estrous ewe: comparison with blood serum and ram seminal fluid. In The Biology of Spermatozoa pp 174-181 Eds ESE Hafez and CG Thibault. Basel Press, New York

Miller JGO and Schultz GA (1987) Amino acid content of preimplantation rabbit embryos and fluids of the reproductive tract Biology of Reproduction 36 125-129

Miyoshi K, Abeydeera LR, Okuda K and Niwa K (1995) Effects of osmolarity and amino acids in a chemically defined medium on development of rat one-cell embryos Journal of Reproduction and Fertility 103 27-32

Monesi V and Salfi V (1967) Macromolecular synthesis during early development in the mouse embryo Experimental Cell Research 46 632-635

Nelder JA and Wedderburn RWM (1972) Generalized linear models Journal Review of Statistical Society 135 370-383

Perkins JL and Goode L (1967) Free amino acids in the oviduct fluid of the ewe Journal of Reproduction and Fertility 14 309-311

Quinn P, Warnes GM, Kerrin JF and Kirby C (1985) lmproved pregnancy rate in human in vitro fertilization with the use of a medium based on the composition of human tubal fluid Fertility and Sterility 44 493-498

Renard JP, Philippon A and Menezo Y (1980) In-vitro uptake of glucose by bovine blastocysts Journal of Reproduction and Fertility 58 161-164

Rieger D, Loskutoff NM and Betteridge KJ (1992) Developmentally related changes in the uptake and metabolism of glucose, glutamine and pyruvate by cattle embryos produced in vitro. Reproduction Fertility and Development 4 $547-557$

Schultz GA, Kaye PL, McKay DJ and Johnson MH (1981) Endogenous amino acid pool sizes in mouse eggs and preimplantation embryos Journal of Reproduction and Fertility 61 387-393

Spindle AI and Pedersen RA (1972) Hatching, attachment, and outgrowth of mouse blastocysts in vitro: fixed nitrogen requirements Journal of Experimental Zoology 186 305-318

Takahashi Y and First NL (1992) In vitro development of bovine one-cell embryos influence of glucose, lactate, pyruvate, amino acids and vitamins Theriogenology $37963-978$

Telford NA, Watson AJ and Schultz GA (1990) Transition from maternal to embryonic control in early mammalian development: a comparison of several species Molecular Reproduction and Development 26 90-100

Thompson JG, Simpson AC, Pugh PA and Tervit HR (1992) Requirement for glucose during in vitro culture of sheep preimplantation embryos Molecular Reproduction and Development 31 253-257

Thompson JG, Gardner, DK, Pugh, PA, McMillan WH and Tervit HR (1995) Lamb birth weight is affected by culture system utilized during in vitro pre-elongation development of ovine embryos Biology of Reproduction $\mathbf{5 3}$ 1385-1391

Tsai F and Gardner DK (1994) Nicotinamide, a component of complex culture media, inhibits mouse embryo development in vitro and reduces subsequent developmental potential after transfer Fertility and Sterility 61 376-382

Van Winkle LJ (1988) Amino acid transport in developing animal oocytes and early conceptuses Biochimica et Biophysica Acta 947 173-208 
Van Winkle LJ, Haghighat N and Campione AL (1990) Glycine protects preimplantation mouse conceptuses from a detrimental effect on development of the inorganic ions in oviductal fluid Journal of Experimental Zoology 253 215-219

Van Winkle LJ, Mann DF, Wasserlauf HG and Patel M (1992) Mediated $\mathrm{Na}^{+}$-independent transport of L-glutamate and L-cystine in I- and 2-cell mouse conceptuses Biochimica et Biophysica Acta 1107 299-304
Whittingham DG (1971) Culture of mouse ova Journal of Reproduction and Fertility 14 7-21

Zhang X and Armstrong DT (1990) Presence of amino acids and insulin in a chemically defined medium improves development of 8-cell rat embryos in vitro and subsequent implantation in vivo. Biology of Reproduction $\mathbf{4 2}$ $662-668$ 